\title{
A paulada erudita d'um Leminski popular: o problema da língua na literatura brasileira pela perspectiva de dois poemas
}

The erudite whack of a popular Leminski: the Brazilian literature language problem in two poems

\author{
Keissy Guariento Carvelli \\ Universidade Estadual de Paulista Júlio Mesquita Filho, Faculdade de Ciências e Letras, \\ Ricardo André Ferreira Martins ${ }^{2}$ \\ Universidade Estadual do Norte do Paraná, Faculdade de Filosofia, Ciências e Letras,
Jacarezinho, PR, Brasil
}

Doutoranda em Literatura pela Universidade Estadual de São Paulo Júlio Mesquita Filho (UNESP-Assis).

(iD) https://orcid.org/0000-0003-2160-9782

E-mail: keissycarvelli@gmail.com

Doutor em Teoria e História pela Universidade Adjunto do Colegiado de Letras da Faculdade de Filosofia, Ciências e Letras da Universidade Estadual do Norte do Paraná (UENP). (D) https://orcid.org/0000-0002-5291-3405
RESUMO: 0 artigo explora a atualização do problema da língua pela perspectiva de dois textos do poeta Paulo Leminski (1944-1989): o poema "Invernáculo" (1986) e o conto semiótico "O assassino era o escriba" (1985). Apresentam-se, inicialmente, as relações entre a formação do estado nação e das comunidades linguísticas, lançando mão dos conceitos de Pierre Bourdieu (1997) e da concepção histórica de Eric Hobsbawm (1990). Ainda, mobilizam-se os processos de gramatização da Língua Portuguesa no Brasil, tendo como foco as formulações do romancista José de Alencar, considerando as reivindicações por uma linguagem literária genuinamente brasileira. Assim, o problema da língua será apresentado em Paulo Leminski como grau máximo de atualização do tema, demonstrando pontos de contato com a tradição da ruptura, conceito caro à Literatura Brasileira.

Palavras-chave: Literatura Brasileira; Língua Portuguesa; Paulo Leminski.

ABSTRACT: This article explores the updating of the language problem through the perspective of two texts by the poet Paulo Leminski (19441989): the poem "Invernáculo" (1986) and the semiotic tale "The murderer was the scribe" (1985). First, the relations between the formation of the nation state and the language communities are presented, using the concepts of Pierre Bourdieu (1997) and the historical conception of Eric Hobsbawm (1990). Also, the processes of grammarization of the Portuguese Language in Brazil are mobilized, focusing on the formulations of the novelist José de Alencar, considering the claims for a genuinely Brazilian literary language. Thus, the problem of language will be presented in Paulo Leminski as the maximum degree of updating of the theme, demonstrating points of contact with the tradition of rupture, a valuable concept to Brazilian Literature.

Keywords: Brazilian Literature; Portuguese Language; Paulo Leminski. 


\section{Introdução}

obre as "facetas poliédricas" (PELLEGRINI, 2014, p. 13) de Paulo Leminski (Curitiba, 1944-1989), é Domingos Pellegrini quem se debruça a apresentá-las na obra Minhas Lembranças de Leminski (2014), espécie de biografia-memória-ficção, na qual procura traçar os elementos de algumas delas, onze no total. Para além dessas facetas, outra pouco visitada nos estimula pela possibilidade que tem de suscitar atualizações em proposições caras à história da Literatura Brasileira. Trata-se do tributo à tradição literária a partir da retomada do problema da língua.

Em Leminski: o poeta da diferença (2012), Elizabeth Rocha Leite sugere uma divisão da obra do poeta em duas fases: a primeira de 1960 a 19801, caracterizada pela influência do movimento concretista e pela preocupação com os planos da linguagem; e a segunda, a partir de 1980, com menor grau de influência concretista, além da mobilização de questões éticas e existenciais. É possível, porém, traçar com mais cuidado três principais momentos na produção de Paulo Leminski: a) De 1960 a 1970, fase estritamente poética e de influência concretista; b) De 1970 a 1980 (a mais poliédrica): publicação de Catatau (1973), seguida de formulações de um projeto "pós-catatau"; intensa colaboração em revistas literárias "nanicas"2; aproximação com a música - integrou como letrista o grupo de rock curitibano A Chave

\footnotetext{
Os primeiros poemas de Leminski figuram no curso da história literária pela primeira vez em 1964, na edição número 4 da revista Invenção, editada pelo concretista Décio Pignatari (MÜLLER in SANDMANN, 2010, p. 12). No ano seguinte, outros poemas saem na quinta edição do mesmo periódico. A influência dos concretistas para Leminski, para além do dado histórico, também pode ser percebida nas cartas que enviou a Régis Bonvicino, ao denominar, com frequência, os irmãos Campos e Décio Pignatari de "os patriarcas" (1999, p. 51).

2 As revistas chamadas "nanicas" foram publicações de pequeno porte e tiragem "atípicas, protiAs revistas chamadas nanicas foram publicações de pequeno porte e tiragem "atípicas, protitípicas, não típicas, coletivas, antologicas", feitas de maneira coletiva e pelo modo da auto-edição (MELO in BONVICINO, p. 179). Leminski participou ativamente de algumas delas: Corpo Estranho; Poesia em Greve; Polo Cultural/Inventiva; Raposa; Muda; todas publicadas entre as décadas de 1970
e 1980 .
}

(1977); e, ainda, momento de diálogo com o movimento Tropicalista; c) De 1980 a 1987 a fase é sistematizada sumariamente pelo trabalho de tradução ${ }^{3}$ e da crítica ${ }^{4}$ simultaneamente, é também a fase em que o poeta inicia a publicação sistematizada de outra grande série de poemas ${ }^{5}$.

Um trânsfuga por excelência, o cerne da crítica leminskiana está, porém, na transitoriedade da segunda metade de 1970 até 1987, portanto um exercício que se manifestou entre a segunda e terceira fase de sua produção. E é nessa transição, mais de um século após as formulações sobre a linguagem literária travada por José de Alencar, que Leminski retoma o problema da língua atualizando-o num momento em que a discussão já parecia ter sido superada.

Como afirma T.S Eliot, a comparação crítica entre os distintos projetos literários possibilita identificar aquilo que é "permanente ou eterno na poesia, e o que é meramente a expressão do espírito de uma época, e ao descobrir o que muda, como e por que se dá essa mudança, tornamo-nos capazes de perceber o que não muda" (ELIOT, 2015, p. 40). Nesse sentido,

${ }^{3}$ Foram nove traduções produzidas entre 1984 e 1987, oito delas encomendadas pela editora Brasiliense. São elas: Pergunte ao Pó (1984), de John Fante; Vida sem fim (1984), de Lawrence Ferlinghetti; $O$ supermacho (1985), de Jerry Alfred; Giacomo Joyce (1985), James Joyce; Um atrapalho no trabalho (1985), John Lenon; Sol e Aço (1985), Yukio Mishima; Satyricon (1985), Petrônio; Marlone Morre (1986), Samuel Beckett; Fogo e água na terra dos deuses (1987), Poesia egípcia antiga. A totalidade dos textos que constituem os Anseios teóricos 2 (2001) são, na origem, introduções, posfácios e ensaios sobre as obras traduzidas.

${ }^{4}$ Além dos ensaios críticos organizados em livro pelas editoras Criar, Polo Editorial Paraná e Editora Unicamp, há reflexões críticas do poeta que devem ser consideradas, como as realizadas através dos círculos de discussões que, mais tarde, foram publicadas, tais como: Poesia paixão da linguagem, em Os sentidos da paixão, São Paulo: Ed. Companhia das Letras, 1987 (p. 283-291); também o bate-papo realizado pela Biblioteca Pública do Paraná, Um leitor na biblioteca, publicado em 1985, além de entrevistas cedidas à revista literária Nicolau, entre outras.

5 Data dessa década a publicação das seguintes obras de poesia: Polonaises, edição do autor de 1980; Não fosse isso e era menos, não fosse tanto e era quase (1980) pela editora Zap. Caprichos e relaxos Não fosse isso e era menos, não fosse tanto e era quase (1980) pela editora Zap; Caprichos e relaxos (1983), publicado pela Brasiliense, incluindo parcialmente as duas obras anteriores; Hai Tropikais (1985) com Alice Ruiz, publicado pelo Fundo Cultural de Ouro Preto; e Distraídos Venceremos (1987) público - mencionada por Elson Froes, disponível no site Kamiquase, inteiramente dedicado a Leminski. 
o problema da língua ultrapassa as preocupações do espírito de uma época, permanecendo como fonte inesgotável de reflexões também na literatura das décadas finais do século XX.

De modo inicial e breve, procuraremos apresentar as relações entre a formação do estado nação e das comunidades linguísticas, lançando mão dos conceitos de Pierre Bourdieu (1997) e da concepção histórica de Eric Hobsbawm (1990). Após essa breve ambientação, traremos à vista os processos de gramatização da Língua Portuguesa no Brasil, mobilizando algumas das formulações críticas sobre o tema do romancista José de Alencar, expoente primeiro da reivindicação pela liberdade de transformação da língua. Nesse momento, procuraremos exaltar o problema da língua suscitado por Alencar como elemento permanente no projeto fundador de uma linguagem literária.

Por fim, buscaremos pontos de atualização do problema da língua na reivindicação de Paulo Leminski poeta expoente de "uma das últimas gerações de vanguarda" (CABAÑAS, 2014), a de 1970. Foram selecionados dois textos que contemplam a temática: o poema "Invernáculo", espécie de epílogo do livro crítico Anseios crípticos, ensaios teóricos (1986); e o miniconto "O assassino era o escriba", publicado pela primeira vez em 1983, na seção "contos semióticos" do livro de poesias Caprichos \& relaxos.

\section{Língua e formação do Estado Nacional}

A dicotomia entre língua e dialeto, formulada por Pierre Bourdieu, leva em conta os processos propriamente políticos e simbólicos da língua, elementos tão fundamentais quanto sua dinâmica estritamente interna, como propôs o "pai da linguística", Ferdinand de Saussure, cuja teoria foi utilizada como ponto de partida para a contraproposta de Bourdieu em Economia das trocas linguísticas (2008). Oposta ao dialeto, a língua se beneficia de condições institucionais, políticas e econômicas para assimilação. Por isso, frequentemente, é operada via imposição, caso do decreto de Marquês de Pombal $^{6}$, por exemplo.

Para o teórico, são concomitantes os processos de constituição do Estado e da unificação linguística, momento cujos dialetos cedem espaço progressivo à língua oficial. Neste sentido, infere ser imprescindível a unificação do mercado linguístico para a imposição de um modo de expressão em relação aos diferentes dialetos (classistas, regionais ou étnicos) que constituem uma sociedade. Ou seja, a certificação de supremacia de uma voz em relação às distintas vozes sociais: a voz do Estado.

A língua oficial está enredada com o Estado, tanto em sua gênese como em seus usos sociais. É no processo de constituição do Estado que se criam as condições da constituição de um mercado linguístico unificado e dominado pela língua oficial: obrigatória em ocasiões e espaços oficiais (escolas, entidades públicas, instituições políticas etc.), esta língua de Estado torna-se a norma teórica pela qual todas as práticas linguísticas são objetivamente medidas (BOURDIEU, 2008, p. 32).

A unificação linguística também assume ser um critério constitutivo, em Eric Hobsbawm, do estado-nação, cujo triunfo definitivo se dá com o liberalismo burguês de 1830 a 1880. Embora teoricamente a dominação de um território mais ou menos homogêneo regido por políticas unificadas seja o princípio da nação, o historiador elenca outros três critérios fundamentais para o triunfo do modelo político europeu que, de maneira óbvia, se estende ao Brasil via Portugal: a) a associação histórica deste Estado com outro já existente, portanto com um passado que o afirme; b) a existência de uma

6 Fato associado à chamada "vitória da Língua Portuguesa”, o decreto de Marquês de Pombal, em 1758, torna obrigatório o uso da língua lusa no território colonial brasileiro (VITRAL, 2001, p. 304). 
elite cultural longamente estabelecida, além de um vernáculo administrativo e literário escrito; c) uma prova da capacidade para a conquista de território (HOBSBAWM, 1990, p. 49-50).

Dos critérios descritos por Hobsbawm, o Brasil do século XIX já supria com grau de excelência o primeiro e o terceiro deles, com as conquistas portuguesas do maior território sul-americano, inclusive avançando durante esse século sobre o Amapá após a expulsão definitiva dos espanhóis (PRADO JÚNIOR, 2002, p. 1146-1147). Tratando-se do estabelecimento de uma elite cultural, a transferência da corte portuguesa para a colônia a partir de 1808 - e os processos políticos e culturais que dela decorrem - também é um passo definitivo para o nascimento na nação.

Há, porém, uma lacuna quando se trata de um "quase" critério, muito bem observado por Hobsbawm: não basta existir uma elite estabelecida. Além disso, é necessário um vernáculo administrativo e literário escrito que capacite o estado do status de nação. Se os “(...) costumes linguísticos não são passíveis de modificação por decretos (...)” (BOURDIEU, 2008, p. 38), não caberia ao povo brasileiro fundamentar uma língua portuguesa do dia para noite, antes e após o decreto de Pombal. Assim, as escolas literárias são marcadas por exercerem papel fundamental quando se trata da produção e sistematização de vasto material histórico-cultural capaz de fundamentar tanto uma língua quanto um povo - ou ao menos uma ideia de povo.

É justamente nessa grande janela contextual da formação e sistematização da Língua Portuguesa no Brasil, que se fundam as duas dentre as principais vias de disseminação e fixação da língua portuguesa: a Literatura Brasileira (via Romantismo) e a "gramatização brasileira". Ambas se retroalimentam e caminham mais ou menos sob os mesmos passos, embora a literatura assuma uma função a mais - geralmente na contramão dos gramáticos: a de reivindicação pela liberdade de linguagem.

\subsection{Língua, nacionalidade e dissonância}

Concomitante à dizimação das populações ${ }^{7}$ e das línguas indígenas ${ }^{8}$, insurge a história da "gramatização brasileira" que, de acordo com Eduardo Guimarães (1996), pode ser dividida em quatro períodos: a) o primeiro de 1500 até a primeira metade do século XIX, momento fundamental de acalorados debates entre portugueses e brasileiros com intensas polêmicas sobre construções consideradas inadequadas por escritores ou gramáticosportugueses; b) o segundo período se estende da segunda metade do século XIX até fins da década de 1930, tendo como marco a fundação das Faculdades de Letras no Brasil (Faculdade de Filosofia, Ciências e Letras da USP, em 1937, e a Faculdade Nacional de Letras da Universidade do Brasil, em 1939; c) o terceiro é um período mais curto, da década de 1930 até a década d 1960, com a obrigatoriedade da Linguística como disciplina para os cursos de Letras; d) e, por fim; a partir da década de 1960 com a sistematização ampla tanto da Linguística em todos os cursos de graduação em Letras, quanto dos cursos de Pós-graduação (GUIMARÃES, 1996, p.128).

Datada a partir da segunda metade do século XIX, justamente na transição da primeira para a segunda fase da gramatização da língua portuguesa no Brasil, a perspectiva dissonante do problema da língua ganha fôlego com o

trabalho de demonstrar que o Português que aqui se falava e escrevia era diferente do Português de Portugal. Há estudos sobre o léxico, por exemplo, no sentido de mostrar que no Brasil o Português incluía palavras

7 Estudos elaborados por MATTOS e SILVA (2001), tendo como fonte Alberto Mussa, afirmam que, de 1538 a 1600, o Brasil contava com uma população indígena de 50\%; europeus já somavam 30\%; e 20\% de africanos. Já de 1851 a 1890, a estimativa é de apenas 2\% de índios; $17 \%$ europeus; $24 \%$ brancos de africanos. Já de 1851 a 1890, a estimativa e de apenas $2 \%$ de índios; $17 \%$ europeus; $24 \%$ brancos 8 brasileiros; $42 \%$ mulatos; $13 \%$ negros brasileiros e $2 \%$ africanos.

Um dos fatores fundamentais para o desaparecimento de grande parte das variações linguísticas do Brasil é a dizimação indígena nos primeiros três séculos de colonização, sem contar a massiva chegada de europeus e africanos na condição de escravos que acabaram por contribuir com a predominância da língua portuguesa, resultando em um território unilíngue. 
de origem africana e indígena bem como palavras do Português que no brasil significavam diferentemente que em Portugal (GUIMARÃES, 1996, p. 127) ${ }^{9}$.

Figura central dessa ruptura é de José de Alencar (1829-1877), representando o marco fundamental que encerra o primeiro período (de 1500 até a primeira metade do século XIX) e inaugura o segundo - da segunda metade do século XIX até aproximadamente a década de 1930 (GUIMARÃES, 1996).

Na cronologia das "datas icebergs" (BOSI, 1992), o ano de 1857 é representativo pelo fato de ter sido publicado, por Brás da Costa Rubim, o Vocabulário Brasileiro, primeira tentativa tupiniquim de complementar os dicionários da língua portuguesa a partir dos usos da língua. É, porém, em 1870 que uma série de polêmicas envolvendo escritores e gramáticos colocam em xeque, definitivamente, o problema da língua (GUIMARÃES, 1996). Afrânio Coutinho também tributa à geração de 1870 a realização de uma série de modernizações motivadas por concepções sociológicas da cultura, entre elas a fundamental "incorporação da língua brasileira à literatura e seu reconhecimento como uma variedade legítima" (COUTINHO, 1972, p. 381).

Em 1870 se dá a conhecida polêmica entre José de Alencar e o português Pinheiro Chagas. Pinheiro Chagas fez críticas à linguagem de Alencar em Iracema. Alencar responde em um postscrito na segunda edição. As críticas de Pinheiro Chagas são relativamente a neologismos e certas construções gramaticais: uso do artigo, omissão do se reflexivo de certos verbos, e a famosa questão a colocação dos pronomes pessoais (GUIMARÃES, 1996, p. 129).

\footnotetext{
9 O autor cita alguns desses estudos: Gramática História da Língua Portuguesa (1879); Gramática da Língua Portugueza (1887); Gramática Analítica (1887); Gramática Descritiva (1894).
}

Envolvido em uma série de polêmicas, José de Alencar aprimorou tentativas de modernizar a língua portuguesa - via linguagem literária -, dissociando-a dos rigores gramaticais lusos e aproximando-a dos usos brasileiros. De modo geral, Alencar desempenhou um duplo papel: o de afirmação da integração linguística nacional, fundamental à constituição do estado-nação e consoante aos ideais do Romantismo; e o de resistência em relação aos chamados "ocidentalistas" da língua portuguesa, uma perspectiva de dissonância e ruptura.

Alencar é o modelo de corrente que se pode chamar "brasilista" em oposição aos "ocidentalistas". Estes últimos insistem nas raízes ocidentais, brancas, da nossa civilização e cultura; enquanto os primeiros acentuam o lado nativista, brasileiro, construído pelos brasileiros, numa situação geográfica, racial, histórica e social diferente, um novo complexo cultural (COUTINHO, 1974, p. 68).

O romancista aprimorou as formulações de modernizar a língua portuguesa numa tentativa de dissociar a linguagem literária dos rigores da gramática portuguesa, de modo que reivindicou aos escritores brasileiros intelectuais e pensadores de um modo geral - a autoridade para modificá-la de acordo com a necessidade e seus usos. Para Alencar, já no final do século XIX, em Carta ao Sr. Joaquim Serra (1874), inibir os sucessivos movimentos da linguagem portuguesa em solo brasileiro seria como "aleijar nossa língua tão rica" (ALENCAR, 1874, p. 162).

Tributando a favor dos movimentos necessários à língua e contrariando os hábitos da escola classicista que pretende manter, em plena metade do século XIX, a "mesma frase singela da adolescência da língua, quando a educavam os bons escritores dos séculos XV e XVI" (ALENCAR, 1856, p. 108), o ficcionista evidencia concepção modernizadora da língua muito próxima da concepção sociológica de Bourdieu, posto que, mesmo fundamentada por regras fixas, escapa aos rigores rumo às movimentações necessárias para sua própria sobrevivência e reinvenção. 
Por isso, milita abertamente contra a "deplorável exageração dessa regra", responsável por "eliminar as balizas tão claras das diversas línguas" (ALENCAR, 1856, p. 107), afirmando ter a língua capacidade suficiente para romper "as cadeias que lhe querem impor, e vai se enriquecendo já de novas palavras, já de outros modos diversos de locução" (ALENCAR, 1856). Caberia, assim, a reivindicação legítima para modificar a língua oficial e acrescentar-lhe o "genuíno teor de locução", segundo o próprio autor, escapando das "teias de umas regrinhas mofentas" (ALENCAR, 1856, p. 160), referindo-se ao rigor da gramática lusa.

Se no campo político o progresso deveria se realizar através dos projetos de independência, nacionalidade e autonomia, princípios constituintes do estado-nação, o projeto fundador da Literatura Brasileira seguiria passos alinhados a essas concepções. Para isso, não caberia à língua fixar-se às engrenagens que colocaram a máquina em movimento até ali:

Não é obrigando-a [a língua] a estacionar que hão de manter e polir as qualidades que porventura ornem uma língua qualquer; mas sim fazendo que acompanhe o progresso das idéias e se molde às novas tendências do espírito, sem contudo perverter sua índole e abastardar-se (ALENCAR, 1864, p. 108).

Alencar é enfático ao propor a marcha do progresso também à língua, mostrando-a como palco de disputas, uma vez que entram em jogo as especificações simbólicas da língua, como quer mostrar Pierre Bourdieu:

Falar de $a$ língua, sem qualquer outra especificação, como fazem os lingüistas, é o mesmo que aceitar tacitamente a definição oficial da língua oficial de uma unidade política: nos limites territoriais desta unidade, esta língua é a que se impõe a todos os que pertencem àquela jurisdição como a única legítima, e de maneira tanto mais imperativa quanto mais oficial (palavra que traduz precisamente o formal dos lingüistas de língua inglesa) for a circunstância (BOURDIEU, 1997, p. 32).
A reivindicação no campo literário é pautada por Alencar a partir de exemplos colhidos nos usos da oralidade: "Há de saber que nossos irmãos de origem e língua riem-se de nosso povo brasileiro porque diz "moro $n a$ rua de..., estou na janela, cheguei em casa” (ALENCAR, 1856, p. 161). A observação do riso como advertência ao falar errado do povo brasileiro em relação à língua portuguesa de origem demonstra a consciência sociológica das economias das trocas linguísticas: "A questão não é rir (...), mas sim de quem tem razão para rir e tachar-nos como defeito naquela usual locução" (ALENCAR, 1856, p. 161).

A astuta perspectiva indica a afirmação de uma linguagem literária muito mais comprometida com a língua do povo, ainda que considerada errada, do que com a língua do estado (oficial). Para tanto, esclarece o lugar "não autorizado" de onde fala: "Não sou filólogo, nem pretendo para mim os foros de gramático (...)” (ALENCAR, 1856, p. 161). E, ainda assim, reivindica o papel fundamental dos escritores brasileiros (poetas, ficcionistas e críticos) de contribuir para a "revolução da linguagem", da qual, afirma Alencar, já era possível notar os primeiros traços daquilo que chama de "dialeto brasileiro". Ou seja, pretende afirmar pela crítica uma linguagem literária mais alinhada aos movimentos do dialeto do que aos rigores da gramática oficial.

As línguas, como todo o instrumento da atividade humana, obedecem à lei providencial do progresso; não podem parar definitivamente. As pausas, e até mesmo os atrasos, que lhes sobrevenham não passam de acidentes, e de ordinário sucedem-se recrudescências de energias que reparam aquelas perdas (ALENCAR, 1856, p.175).

Obedecer à "lei providencial do progresso" indica a reivindicação pelo "direito de imprimir o cunho de sua individualidade, abrasileirando o instrumento das ideias" (ALENCAR, 1856, p. 160). Com isso, além de lutar por uma linguagem literária que leve em conta a língua corrente do público, 
coloca em evidência as disputas linguísticas operadas e subvertidas por escritores e poetas. Ainda mais, segundo o trecho acima, apresenta-nos a perspectiva de que as pausas e atrasos na movimentação da linguagem, tal qual a que esteve envolvido, resultam em forças energéticas de subversão ainda mais intensas, para que sejam capazes de repararem as perdas sofridas. Essa força de alta voltagem viria pela pena da moderna poesia brasileira do século XX, cuja chave motriz dos projetos vanguardistas intencionava, em grande parte, a liberdade de experimentação no campo da linguagem.

O que José de Alencar pode nos proporcionar com suas reflexões sobre as disputas entre língua portuguesa e linguagem literária é a observação, ainda que sutil, de um elemento que se mostrará permanente - e latente - na moderna poesia brasileira do século XX: a língua como resistência e rebeldia. Nesse sentido, a língua assume papel fundamental na tradição da ruptura, conceito caro a Antônio Candido, para quem o Romantismo representa a ruptura dorsal da Literatura Brasileira, pelo que propõe de libertação em relação às normas literárias preestabelecidas, além do estímulo à experimentação linguística.

Assim, a tensão dissonante proposta por Alencar na discussão sobre a linguagem literária, afim ao termo aplicado por Hugo Friedrich (cf. FRIEDRICH, 1978, p. 16), irá se instaurar como programa especialmente em textos expoentes da moderna poesia brasileira do século XX, caso específico da mini-poética de Mário de Andrade contida em Prefácio Interessantíssimo (1921), por exemplo.

Mais de século após as primeiras grandes polêmicas instauradas por José de Alencar, o problema da língua mostra-se ponto de contato em alguns momentos da obra do poeta contemporâneo Paulo Leminski (19441989), objetivo fundamental da pesquisa aqui proposta. Para tanto, o foco da presente análise comparativa está concentrada em dois textos, são eles:
"Invernáculo" (3) ${ }^{10}$ e "O assassino era o escriba"11. Assim, procura-se, mais que comparar, compreender os momentos de atualização do problema propostos por Leminski.

\section{Esta língua não é minha}

O poema "Invernáculo" (3) ${ }^{12}$, escrito por Paulo Leminski entre as décadas de 1970 e 1980 é um ponto contemporâneo de contato com a discussão que travamos até aqui. Cabe a reprodução integral:
Esta língua não é minha,
qualquer um percebe.
Quando o sentido caminha,
a palavra permanece.
Quem sabe mal digo mentiras,
Vai ver que só minto verdades.
Assim me falo, eu, mínima,
quem sabe, eu sinto, mal sabe.
Esta não é minha língua.
A língua que eu falo trava
uma canção longínqua,
a voz, além, nem palavra.
0 dialeto que se usa
à margem esquerda da frase,
eis a fala que me lusa,
eu, meio, eu dentro, eu quase
(LEMINSKI, 1986, p. 7).

A começar pelo título, o neologismo nos indica o percurso de um poema que, desde o princípio, tributa pela negação da língua vernácula através

${ }^{10}$ Poema publicado pela primeira vez como epílogo de Anseios Crípticos (Anseios teóricos): peripécias de um investigador no sentido no torvelinho das formas e das idéias (1986). Mais tarde, integra o livro

póstumo de poemas inéditos O ex-estranho (1996).
11 Poema publicado na seção Contos Semióticos de Caprichos \& relaxos (1986).

${ }^{12}$ Reproduzido aqui de sua Toda Poesia (2013). 
da inserção do prefixo de negação in. Sabendo da predileção do poeta pela mistura de línguas na composição de seus versos - com grande frequência o inglês, francês espanhol e latim -, torna-se possível inferir ao prefixo o sentido da preposição dentro, se pensarmos no termo in em referência à língua inglesa. Nesse caso, trata-se também de um poema escrito a partir das discussões intrínsecas ao problema do vernáculo.

A consciência dos primeiros versos "Esta língua não é minha,/ qualquer um percebe", assume a posição de um poema constituído por uma língua que não lhe pertence, e, ao poeta, cabe assumir corajosamente o seu não pertencimento àquela comunidade linguística. A negação, como peça propulsora do poema, pretende superar as reivindicações de românticos em relação ao problema da autonomia para mudar e enriquecer a Língua Portuguesa dos escritores brasileiros. Os versos leminskianos querem mais e, por isso, nega.

Não há mais espaço para modernizar ou nacionalizar a língua. Ao contrário, só há espaço para a tomada de consciência histórica e crítica sobre os processos políticos e culturais de imposição da língua. Do mesmo modo, cabe solidificar as vantagens indiscutíveis do dialeto como matéria-prima para a linguagem poética, colocadas em jogo nos versos seguintes: "quando o sentido caminha,/a palavra permanece". Aí fica clara a pretensão de expor a dualidade entre a rigidez da estrutura linguística, na imagem da palavra estática, e a fluidez dos sentidos provocados pelos seus usos e movimentos. O tributo, como mostram os versos, tende ao dialeto.

A repetida afirmação "esta língua não é minha" reforça a ideia de que o poeta não deixou escapar em seus primeiros versos uma infâmia ou um desvio da norma poética. Basta retomar a advertência de José de Alencar, ao ponderar que a revolução da linguagem deve ir até o limite possível de não nos abastardarmos “(...) fazendo que acompanhe o progresso das idéias (sic) e se molde às novas tendências do espírito, sem contudo perverter sua índole e abastardar-se" (ALENCAR, 1864, p. 108). Leminski, ao contrário, assume uma infâmia, um exílio, uma dominação, assume-se bastardo: "essa língua não é minha, qualquer um percebe". Exaltados, os versos dão um passo além no curso das discussões pinçadas até o momento, indicando a tomada de consciência crítica e histórica, via poesia, da língua como produto simbólico de colonização e hierarquização.

Se a língua é a foice do operário poeta, segundo Mário de Andrade, "O operário não compra a foice, apenas, tem de afiá-la dia por dia” (ANDRADE, 1974, p. 246), e o poeta é a "antena da raça”, segundo Ezra Pound (1973), trata-se da epifania de um trabalhador que, olhando a ferramenta em suas mãos, compreende ter ela muito mais que uma função social de afirmação da pátria ou de formulação da modernidade: é, a foice, ferramenta de dominação. Portanto, traz consigo o caráter de resistência, de dissonância e de experiência revolucionária - no campo puramente linguístico, musical e estético, como atenta Herbert Marcuse, ao afirmar ser a forma e a função da arte, na situação do século XX, a da recusa e destruição (MARCUSE, 2000, p. 262).

Sempre disposto a evocar sentidos múltiplos com a simplicidade de quem não os intenciona, os versos provocam: "A língua que eu falo trava/ uma canção longínqua". A pausa entre os versos e a não dependência semântica entre eles proporcionam interpretação de duplo sentido. Lido somente o primeiro verso, recorremos ao sentido de uma língua que por seus inúmeros problemas, inclusive o de origem - tem seu percurso interrompido justamente por não lhe ser língua íntima. Por isso, mostra-se como uma língua que emperra e é impedida de se movimentar, uma língua não fluída. No entanto, a sequência nos indica outro sentido do termo "trava", como sinônimo do verbo lançar mão e valer-se de, inferindo à ideia composta de uma língua que não flui facilmente justamente porque se vale de origens 
longínquas e pouco familiares. Vale ressaltar também a associação sonora provocada pela relação entre os termos "trava" e "palavra", de modo que podemos inferir o sentido de que aquilo que impede o movimento da língua é justamente a dificuldade da palavra.

Em contrapartida à língua estranha que não foge de seus rigores, é evocada a imagem do dialeto, ferramenta de comunicação que, segundo Pierre Bourdieu (2008), não se beneficia exclusivamente de constituições institucionais para consolidação, por isso traz consigo o princípio que subvertem a língua: a liberdade de uso e mudanças.

\section{0 dialeto que se usa}

à margem esquerda da frase,

eis a fala que me lusa,

eu, meio, eu dentro, eu quase (LEMINSKI, 1986, p. 7).

O dialeto é encarado como marginal ao andar "à margem esquerda da frase". Ou seja, funda-se fora da gramática e, como outsider, solidifica-se do lado oposto à rigidez semântica: na poesia. Consciente de uma filiação linguística imposta via colonização, os versos recorrem ao dialeto como meio de comunicação e produção de sentidos, como no jogo criativo de "Eis a fala que me lusa", em que o poeta nos apresenta a origem da língua estranha da qual faz questão de se desapropriar. Ao fazer uso do termo "lusa" provoca a aproximação sonora da cultura portuguesa com a palavra "usa", para completar a ideia contida no verso de que o poeta é o meio para a constante transformação do dialeto, modo "marginalizado" de se expressar e, portanto, periférico à língua de origem.

Para tanto, a constatação de que os sentidos são da ordem dos movimentos e do "caminhar" arrebata o ímpeto de consolidar, para a linguagem poética, a função de provocar constantes movimentos e pequenas revoluções na gramática.

\subsection{0 assassino era o escriba}

Aos moldes da exclamação de que "esta língua não é minha", "O assassino era o escriba"13 apresenta, de um modo mais irônico e não menos crítico, a problemática entre língua, gramática e linguagem poética. Vejamos na íntegra para posterior análise:

\section{Meu professor de análise sintática era o tipo do sujeito inexistente. \\ Um pleonasmo, o principal predicado da sua vida, regular como um paradigma da 1a Conjugação; \\ Entre uma oração subordinada e um adjunto adverbial, ele não tinha dúvidas: sempre achava um jeito assindético de nos torturar com um aposto. \\ Casou com uma regência. \\ Foi infeliz. \\ Era possessivo como um pronome. \\ E ela era bitransitiva. \\ Tentou ir para os EUA. \\ Não deu. \\ Acharam um artigo indefinido em sua bagagem. \\ A interjeição do bigode declinava partículas expletivas, co- nectivos e agentes da passiva, o tempo todo. \\ Um dia, matei-o com um objeto direto na cabeça \\ (LEMINSKI, 1985, p. 144).}

O poema, já com a sugestão de ser um miniconto semiótico, portanto inteiro composto por signos e símbolos, apresenta como personagem principal o "professor de sintática", figura tradicionalmente ligada à rigidez e aos posicionamentos favoráveis à gramatização da língua. A descrição, no poema, confere com o imaginário: trata-se de um professor muito rígido associado intimamente a diversos termos caros ao ofício de gramático: sujeito, pleonasmo, predicado, conjunção, oração subordinada, adjunto

${ }^{13}$ Reproduzido aqui da 3ạ edição de Caprichos \& Relaxos (1985). 
adverbial, assindético, aposto, regência, pronome possessivo, bitransitiva, artigo indefinido, interjeição, partículas expletivas, conectivos, agentes da passiva e objeto direto. Trata-se, evidentemente, de uma leitura arguta e conhecimento prévio do campo linguístico, da sintaxe propriamente dita.

Diferentemente da análise interpretativa e poética, a função da análise sintática no interior do campo linguístico é a de examinar a estrutura gramatical de um período frasal, encarregando-se de classificar as estruturas que ali se apresentam. A figura do "professor de análise sintática" está voltada à imagem de um mestre rigidamente ligado à lógica estruturante da linguagem: não há campo externo à língua, apenas àquele em que pode desmontar e analisar de muito perto.

No poema, o "professor" nada mais é que um "sujeito inexistente", ou seja, um sujeito que só existe no interior da sintaxe gramatical. De maneira muito articulada, o poema sugere elementos que formam a gramática a qual somos compelidos a aprender como "língua" por estes "professor[es] de análise[s] sintática[s]", de forma que a principal característica inerente a este sujeito é o pleonasmo, figura de linguagem que serve à intensificação redundante de um determinado sentido.

O interessante aqui é a habilidade com que Leminski relaciona características de sentidos "pessoais" às utilizações gramaticais, por exemplo: ao sugerir o predicado principal do "professor" coloca-o entre duas vírgulas, fazendo uso das regras gramaticais como característica formal do poema. Da mesma maneira em "ele não tinha dúvidas: sempre achava um jeito assindético de nos torturar com um aposto" cita o aposto após os "dois pontos", assim como quer a sintaxe. No decorrer do poema as regras gramaticais continuam dando o tom da história: o sujeito professor casa-se com uma "regência", no entanto não foi capaz de manter um relacionamento feliz e a explicação é, justamente, a "regra". o professor, por ser um "pronome possessivo", não aceitou a relação "bitransitiva” de sua esposa-regência.
O sujeito-aluno resolve a questão instaurada no poema - o problema do professor de análise sintática - matando-o com uma das armas de seu próprio trabalho: o objeto direto, aqui suscitando a ideia não de um elemento gramatical, mas de um simples material lançado "direto" na cabeça deste professor, capaz de feri-lo o suficiente para provocar sua morte. Porém, para além da história linear que sugere, o poema traz ainda mais sentidos, se esmiuçado de perto.

A ambivalência se mostra no desfecho. Ao mesmo tempo em que o "aluno/poeta" pretende acabar com o seu próprio problema matando a figura rigorosa do professor que dita as regras, ele mesmo faz o uso exato de todos os elementos inerentes à gramática da língua portuguesa no interior de seu poema. Embora morto, o "professor de sintática" é figura intensa o suficiente para reger toda a escrita que permeia o conto poético. Outro ponto também fundamental é a retomada da linha de pensamento leminskiano abordado em "Invernáculo", cuja língua portuguesa está voltada à figura da rigidez, daquilo que não flui, presa aos esquemas bem montados.

Embora o poeta trabalhe com a língua e que dela deva saber suas nuances e rigores, é necessário que esta "gramática" já solidificada seja "morta" em virtude da produção de uma linguagem voltada à semântica, não à sintaxe. Ligada ao espaço dos sentidos, então, a língua pode servir tanto aos rigores quanto aos relaxos, como faz o poeta nos versos acima. Nesse sentido, a figura do "professor de análise sintática" pode ser relacionada à própria Língua Portuguesa, de modo que "matar" o professor de análise sintática com um objeto direto em sua cabeça significa muito mais que exterminar a figura humana daquele que rege as normas.

Para um leitor comum, distante de toda e qualquer erudição da língua, o total desconhecimento das regras da sintaxe linguística não é uma barreira para a compreensão, ainda que primária, do poema. Isto porque, mesmo que 
não saiba exatamente decifrar todas as camadas de significados provocadas pelo poeta, é capaz de compreender no poema os entraves de uma língua que se baseia em regras minuciosas e por vezes complexas.

Porém, estão nas camadas menos aparentes as análises mais profícuas. Com os efeitos de significados provocados, o poema pode resultar na atualização do problema da língua, ao expor os detalhes de uma língua e superar, com um tom irônico, as disputas entre gramáticos, escritores e poetas. Para isso, é possível retomar o título do poema "O assassino era o escriba", concluindo que, pela perspectiva do conto, cabe ao escriba - figura simbólica voltada à dominação da arte da escrita - a função de romper com a gramática sem perder de vista seus ensinamentos. Assim, assassinar o professor de análise sintática, sumariamente também representa o deslocamento da língua de seus parâmetros objetivos, inserindo-a no campo dos sentidos.

\section{Conclusões}

O percurso elaborado na presente pesquisa possibilitou, de maneira inicial, identificar o problema da língua como assunto permanente do decorrer da Literatura Brasileira, principalmente em momentos de extrema voltagem de experimentações e reivindicações, casos profícuos - e não únicos - de José de Alencar e Paulo Leminski. Embora cronologicamente distantes, e dissociados completamente de objetivos e projetos literários, o que une o romancista ao poeta, ou vice-versa, é justamente a comparação crítica em relação ao tema da língua.

Segundo Eliot, se um problema literário ultrapassa o espírito de sua época, trata-se de uma permanência a ser percebida. Não significa, porém, a afirmação de uma homogeneidade de posicionamentos. Para Afrânio Coutinho (1974), a proposta de um "novo complexo cultural" invariavelmente perpassa o problema da língua atrelado à busca, no campo da literatura, pela expressão nacional autêntica (cf. CANDIDO, 1981, p. 14).

Nesse sentido, José de Alencar traduz exatamente tais propostas, uma vez que:

(...) procurou direcionar sua investigação teórica pela elaboração de uma modalidade nacional da língua portuguesa, a qual iria nutrir a nova narrativa de distintos vocábulos, através das metáforas criadas, além das comparações e digressões do narrador. Nesse contexto, desencadeouse uma preocupação que se tornará constante: investigar qual o estilo propício para a literatura nacional (ABREU, 2003, p. 136).

A constante investigação do estilo e da linguagem nacional, porém, é atualizada. Superados os fins nacionais da literatura após um século de escolas e projetos, o problema da língua também se reinventa. Os dois textos de Paulo Leminski, analisados anteriormente, mostram-se pontes capazes de enriquecer o fluxo contínuo dos debates entre a gramatização da Língua Portuguesa, além de instaurar novas reivindicações pela liberdade de operar e transformar a linguagem literária.

Nesse sentido, mobilizar o poema "Invernáculo" e o conto semiótico "O assassino era o escriba" tem a função primordial de contemplar o aspecto fundamental da trajetória do poeta paranaense, embora ainda pouco observado: o diálogo recorrente com a tradição linguística e a disposição para atualizar problemas, tais como a língua, que se mostram permanentes no curso da Literatura Brasileira.

Para tanto, os textos analisados retomam o problema instaurado por Alencar - e desenvolvido ao longo dos projetos literários do século XX -, numa tentativa de superá-lo. Ou seja, procura, senão responder, ao menos colocar em pauta a grande questão: o que ainda é possível dizer sobre a língua um século após as reivindicações de Alencar e a alta voltagem de 
experiências e formulações de Mário de Andrade e Oswald de Andrade na poesia e na prosa, Guimarães Rosa no romance?

O que o poeta parece propor nos dois textos analisados, acima de tudo, é a reivindicação da consciência histórica, sociológica e literária da língua portuguesa. Em "Invernáculo" a negativa de que "essa língua não é minha" tende às primeiras delas, uma vez que apresenta a língua pela perspectiva das dominações históricas e políticas; já em "O assassino era o escriba" transforma-se em consciência linguístico-literária, uma vez que, desnudando a figura do professor de análise sintática, desnuda também as estruturas da língua. Ainda, atribui ao poeta a função dual de assassino das regras gramaticais e libertador da linguagem semântica.

\section{Referências}

ABREU, Mirhiane Mender de Abreu. A sistematização da linguagem literária em Alencar. Revista Via atlântica, Universidade de São Paulo, v. 6, n. 1, p. 135-145, out. 2003. Disponível em: <http://www.periodicos.usp.br/viaatlantica/article/download/49748/53860>. Acesso em: 13 nov. 2017

ALENCAR, José de. Carta ao Sr. Joaquim Serra (1874). In: COUTINHO, Afrânio (Org.). Caminhos do pensamento crítico. Rio de Janeiro: Ed. Americana, Prolivro, 1974. Vol. II.

ALENCAR, José de. Carta sobre a confederação de Tamoios (1856). In: COUTINHO, Afrânio (Org.). Caminhos do pensamento crítico. Rio de Janeiro: Ed. Americana, Prolivro, 1974. Vol. II.

ALENCAR, José de. Pós-escrito a Diva. (1864). In: COUTINHO, Afrânio (Org.). Caminhos do pensamento crítico. Rio de Janeiro: Ed. Americana, Prolivro, 1974. Vol. II.

ANDRADE, Mário de (1893-1945). Aspectos da literatura brasileira. São Paulo: Martins, 1974.

BOSI, Alfredo. O tempo e os tempos. In: NOVAES, Adauto (Org). Tempo e História. São Paulo: Companhia das Letras: Secretaria Municipal da Cultura, 1992.

BOURDIEU, Pierre. A economia das Trocas Lingüísticas: o que falar quer dizer. São Paulo: Editoria da Universidade de São Paulo, 2008.
CABAÑAS, Tereza. Os surpreendentes caminhos da estética: A poesia marginal dos anos 70 (9-36). Revista Chilena de Literatura, n. 88, dic. 2014. Disponível em: <www. revistaliteratura.uchile.cl/index.php/RCL/article/viewFile/36075/37743>. Acesso em: 03 ago. 2017.

CALLOU, Dinah. Da História social à História Lingüística: O Rio de Janeiro no século XIX. In: ALKMIN, Tania Maria [Org.]. Para a história do Português Brasileiro. São Paulo: Humanitas/FFLCH/USP, 2002. Vol. III: Novos Estudos. p. 281-292.

COUTINHO, Afrânio. Caminhos do pensamento crítico. Rio de Janeiro: Pallas; Brasília: INL, 1972. Vol. I.

DIAS, Gonçalves. Carta ao Dr. Pedro Nunes Leal (1848). In: COUTINHO, Afrânio (Org.). Caminhos do pensamento crítico. Rio de Janeiro: Ed. Americana, Prolivro, 1974. Vol. II.

ELIOT, T. S. O uso da poesia e o uso da crítica: estudos sobre a relação da crítica com a poesia na Inglaterra. Tradução: Cecilia Prada. São Paulo: É Realizações, 2015.

FRIEDRICH, H. Estrutura da lírica moderna. 2. ed. Trad. Marise M. Curioni. São Paulo: Duas Cidades, 1991.

GUIMARÃES, Eduardo. Sinopse dos estudos do português no Brasil: a gramatização brasileira. In: ORLANDI, Eni; GUIMARÃES, E. (Org.). Língua e cidadania: o português no Brasil. São Paulo: Pontes, 1996.

HOBSBAWM, Eric. Nações e nacionalismos desde 1780: programa, mito e realidade. Trad. Maria Celia Paoli, Ana Maria Quirino. Rio de Janeiro: Paz e Terra, 1990.

LEITE, Elizabeth Rocha. Leminski: o poeta da diferença. São Paulo: Editora da Universidade de São Paulo/Fapesp, 2012.

LEMINSKI, Paulo. Envie meu dicionário: cartas e alguma crítica. São Paulo: Editora 34, 1999.

LEMINSKI, Paulo. Toda poesia. São Paulo: Companhia das Letras, 2013.

MAGALHÃES, Domingos José de. Discurso sobre a história da literatura do Brasil (1836). In: COUTINHO, Afrânio (Org.). Caminhos do pensamento crítico. Rio de Janeiro: Ed. Americana, Prolivro, 1974. Vol. II.

MARCUSE, Herbert. A arte na sociedade unidimensional. In: ADORNO, Theodor et al. Teoria da cultura de massa. Comentários e seleção de Luiz Costa Lima. São Paulo: Paz e Terra, 2000. p. 259-270.

PELLEGRINI, Domingos. Minhas lembranças de Leminski. São Paulo: Geração editorial, 2014. 
POUND, E. $O A B C$ da literatura. Trad. Augusto de Campos e José Paulo Paes. 2. ed. São Paulo: Cultrix, 1973.

PRADO JÚNIOR, Caio. Formação do Brasil contemporâneo. In: SANTIAGO, Silviano (Org.). Intérpretes do Brasil. Rio de Janeiro: Nova Aguilar, 2002. Vol. 3.

SILVA, Rosa Virgínia Mattos e. De fontes sócio-históricas para a história social linguística do Brasil: em busca de indícios. In: SILVA, Rosa Virgínia Mattos e. (Org.) Para a história do português brasileiro. São Paulo: Humanitas/FFLCH/USP: FAPESP, 2001. p. 275-302.

VITRAL, Lorenzo. Língua Geral versus Língua Portuguesa: A influência do processo civilizatório. In: SILVA, Rosa Virgínia Mattos e (Org.) Para a história do português brasileiro. Sâo Paulo: Humanitas/FFLCH/USP: FAPESP, 2001. p. 303-315.

Recebido em 17/09/2017.

Aceito em 15/01/2018. 